\title{
A CASE OF PARALYSIS AGITANS, SHOWING UNUSUAL CONTRACTIONS.
}

\author{
BY FRANK P. NORBLRY, M.D.,
}

Jacksonville, III.

Late Assistant Physician Illinois Central Hospital for the Insane. Formerly, Resident Physician Pennsylrania Institntion for Feeble Minded Children.

$\mathrm{M}^{\mathrm{k}}$

RS. R., aged 54 years, insane six years; cause, change of life; was admitted to the Illinois Central Hospital for the Insane, August, i89-. She was emotional and deluded, presenting the usual symptoms of chronic delusional mania, with periodical disturbed spells. The family history was not complete. A sister was insane and is a patient at the same hospital. No special nervous symptoms were noticed on admission, and not until seven months later, were the prodromes of paralysis agitans, noticed.

Her gait first became slower, then the movements of her hands were involved. As she spent the greater por. tion of her quiet intervals in knitting, the interference with her ordinary dextrous movements was noticed by herself and others.

Trembling next appeared, followed by rigidity. Her lower limbs were invaded about the same time, then came restriction of bodily movements, the block of wood type, spoken of by Dercum, being assumed. Facial movements became difficult; the muscles were fixed and eyes staring.

The intellect was dulled, slowness of perception with inability to appreciate surroundings, being especially noticed. Six months later, she was helpless and bedridden; her hands were flexcd, left leg semi-flexed, trunk slightly rotated to the left. Speech was indistinct, there was drivelling of saliva and partial opening of the mouth. Tremor, continuous and regular, increased, but during the last months it disappeared with the onset of fixation of the contracted muscles.

The contractions gradually became more pronounced, and permanent fixation resulted. This rigidity and fixation involved the flexor muscles of the hips, thighs, fore arms, legs, hands, feet, fingers and toes. The right thigh was drawn across the body and over the left leg, 


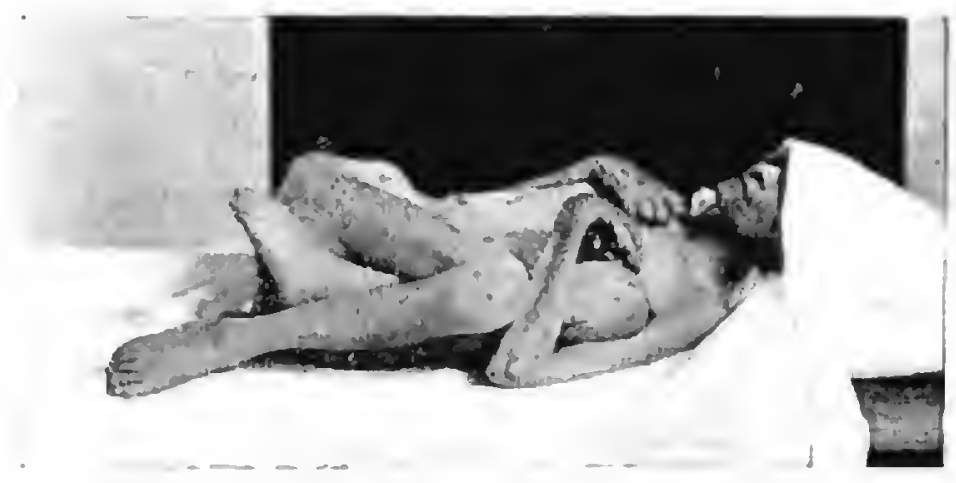

which was flexed upon the thigh, and the thigh upon the body. The flexed fingers were rigid, they overlapped each other in the left hand.

The photograph shows the condition of contractions and rigidity at the time of death, which occurred ten months after the first symptoms of paralysis agitans appeared. Nutrition commenced to suffer about three months before death; emaciation was marked at death. Wherever one limb crossed, or came in contact with another, bed sores formed; they also formed on the back and hips, all in spite of special care and cleanliness. Helpless and demented this pitiable subject lived for three months in this deplorable condition.

This case being an unusual one, the writer thought it worthy of reporting.

A Case of Traumatic Tetanus in an Aboriginal Australian Ending in Recovery.-(Australasian Medical Gasette, No. I2, I 894). Dr. James MIcNish, of North Queensland, Australia, reports a case of traumatic tetanus in an aboriginal Australian, which was treated successfully by bromide of potash and chloral,

- fifteen grains of the former and ten of the latter every three hours.

F. H. P. 